\title{
"SE PREPARE QUE O PAVIO VAI ACENDER": análise sobre o movimento de ocupação do Instituto Federal de Cabedelo/PB
}

\section{“GET READY, THE FUSE IS ABOUT TO LIGHT”: an analysis on the occupation movement of the Federal Institute of Cabedelo/PB}

\author{
Raphaella Ferreira Mendes* \\ Geovânia da Silva Toscano**
}

\section{Resumo}

O presente artigo é proveniente do trabalho de conclusão de curso de uma das autoras (MENDES, 2017), que teve como objetivo investigar o movimento de Ocupação das Escolas no ano de 2016, com ênfase no Instituto Federal da Paraíba (IFPB) campus Cabedelo. O percurso metodológico refere-se ao acesso inicial da pesquisa realizada durante a ocupação do campus através do projeto de extensão intitulado Universidade e Juventude: passarela cidadã. O segundo momento foi a realização de um grupo focal com os alunos e alunas que fizeram parte da ocupação, para desta forma, entender como se dá a relação escola-alunos após o movimento de ocupação. Com a mobilização de alguns teóricos, como Castells (2013), Gohn (2011), Poerner (2004) Foracchi (1972), Ianni (1963), Sposito (2000), Pais (1993), pode-se compreender a trajetória dos movimentos sociais da juventude e a sua dinâmica na contemporaneidade. Nesse sentido, com os resultados, torna-se perceptível uma maior quantidade de participação de alunos mais jovens, concentrados no primeiro ano, e, a partir dos relatos, demonstra-se uma mudança na relação com a escola mediante uma maior apropriação do espaço escolar pelos alunos participantes desta pesquisa.

Palavras-chave: Ocupação; Estudantes; Participação; Resistência.

\begin{abstract}
This article is the product of the author's undergraduate monograph (2017), which aimed to investigate the School Occupation Movement in 2016, at the Federal Institute of Paraíba (IFPB) campus Cabedelo. The methodological approach refers to the initial access carried out during the occupation of the campus through the Extension Project entitled University and Youth: citizen walkway. The second moment refers to the conduct of a focus group with the students who were part of the occupation, in order to understand the dynamic of school-student relationship after the occupation movement. With recourse to theorists such as Castells (2013), Gohn (2011), Poerner (2004) Foracchi (1972), Ianni (1963), Sposito (2000), Pais (1993), it is possible to understand the trajectory of youth

\footnotetext{
* Mestra em ciências sociais pela Universidade Federal de Campina Grande/Brasil. E-mail: raphaellaffm@gmail.com.

** Doutora em ciências sociais pela UFRN/Brasil. Professora do Departamento de Ciências Sociais da UFPB/Brasil. E-mail: geotoscano@gmail.com.
} 
social movements and their dynamics in contemporary times. In this sense, the results reveal a greater amount of participation among younger students, concentrated in the first year, and, on the basis of reports, a change in the relationship with the school is evident through a greater appropriation of the school space by students participating in this research.

Keywords: Occupation; Students; Participation; Resistance.

\section{Introdução}

$\mathrm{Na}$ contemporaneidade, a inconformidade com a realidade social, política e econômica, propiciaram o surgimento de mobilizações como a "Primavera Árabe" em 2011; Occupy Wall Street em Nova York, 2011; "Revolta dos Pinguins" no Chile em 2006, e a Ocupação em Hong Kong em 2014. Focos mundiais de mobilização que têm como perspectiva ocupar um espaço como forma de manifestação e organização, com poder de criar pautas que estão em emergência para cada realidade desses grupos, como apontou Castells (2013).

No Brasil, as mobilizações ocorridas no ano de 2016 resultaram de uma série de acontecimentos no contexto político, dentre eles, o impeachment da presidenta Dilma Rousseff (PT), em 31 de agosto de 2016. Ao assumir a liderança do governo, o vicepresidente, Michel Temer (PMDB), implementou reformas no âmbito econômico e educacional, dentre elas duas propostas que afetariam diretamente os estudantes secundaristas: a reformulação do ensino médio com o Projeto de Lei 6840/2013, tornando-o integral, bem como a elaboração de ciclos escolares que acabariam com a obrigatoriedade da oferta de disciplinas como Artes, Educação Física, Sociologia e Filosofia; além da Proposta de Emenda Constitucional n ${ }^{\circ} 241 / 2016$, ou n ${ }^{\circ} 55$, a depender da casa legislativa tramitada, com objetivo de criar um teto de 20 anos em gastos com setores como a Educação, sendo aprovada em 16 de dezembro de 2016 e se transformando em Emenda Constitucional no 95/2016.

Como uma das formas de resistências a esse contexto, ao longo dos meses de agosto a novembro de 2016, jovens da rede pública de ensino ocuparam mais de mil escolas, institutos federais e universidades públicas em todo o território nacional. A "Primavera Secundarista" foi o nome atribuído a esse fenômeno brasileiro caracterizado 
pela paralisação das atividades escolares rotineiras que promoveram um tipo de resistência diante das medidas impostas pelo novo governo.

$\mathrm{Na}$ Paraíba, algumas escolas serviram de palco para materialização dessas experiências vividas por esses jovens, manifestando ocupações na Universidade Federal da Paraíba, nos campi de João Pessoa, Areia e Bananeiras, bem como na Universidade Federal de Campina Grande, com os campi de Campina Grande e Sumé. Dentre as escolas estaduais ocupadas, estiveram a Escola Estadual Dr. Elpídio de Almeida (conhecida como Gigantão da Prata) em Campina Grande, e o Lyceu Paraibano em João Pessoa (MENDES, 2017).

Segundo a União Brasileira dos Estudantes Secundaristas (UBES), no mesmo período, a Paraíba ainda registrou a ocupação de cinco institutos federais. Dentre eles, segundo Mendes (2017, p. 13) “o Instituto Federal da Paraíba (IFPB) campi João Pessoa, localizado no bairro de Jaguaribe; o de Cabedelo, localizado na grande João Pessoa; Guarabira no agreste paraibano, Sousa e Cajazeiras, no sertão do estado".

A nossa inserção nos estudos sobre as ocupações das escolas envolve um atravessamento pessoal, como aluna oriunda da rede pública de ensino, como também acadêmico, com a aproximação com a Rede Estadual de Ensino de João Pessoa/PB por intermédio do Programa Instituição de Bolsas de Iniciação à Docência (PIBID), no período de 2013 a 2017 na Universidade Federal da Paraíba.

Além disso, tivemos acesso, em 2016, ao questionário sobre a ocupação no Instituto Federal da Paraíba (IFPB) campus Cabedelo aplicado pela equipe do "Projeto de Extensão Universidade e Juventude: passarela cidadã”, vinculado ao Departamento de Ciências Sociais/UFPB. Tais experiências, corroboraram para o desenvolvimento do campo de estudo que resultou no Trabalho de Conclusão de Curso (TCC) desenvolvido na Licenciatura em Ciências Sociais na Universidade Federal da Paraíba.

De acordo com Mendes (2017, p. 14), o Instituto Federal da Paraíba campus Cabedelo representou, dentre as demais escolas ocupadas na Paraíba, "aquela com maior expressividade na região em relação ao período de duração, totalizando 52 dias em que alunos ocuparam o Instituto". Por isso, as perguntas que nortearam a pesquisa foram: como se desenvolveu a ocupação do IFPB campus Cabedelo? Qual o sentido da 
apropriação do espaço escolar pelos jovens? Quem são estes jovens? Como eles, após a ocupação, falam desse espaço escolar?

Neste artigo, analisamos como se desenvolveu o movimento de Ocupação no Instituto Federal da Paraíba (IFPB) campus Cabedelo no ano de 2016, a partir do sentido de apropriação do espaço escolar por parte dos jovens. Caracterizamos como ocorreu a estrutura organizacional do movimento de ocupação no IFPB/Cabedelo, apresentamos o perfil dos alunos que participaram do movimento de ocupação e identificamos como os jovens perceberam o espaço escolar após o processo de ocupação da escola.

Os dados do questionário aplicado em 2016 pela equipe do projeto de extensão da UFPB mobilizaram categorias analíticas fundamentais para a construção do perfil socioeconômico e cultural dos jovens que participaram da ocupação no IFPB/Cabedelo, tais como: idade; sexo; estado civil; escolaridade dos pais; ocupação dos pais; se participaram de alguma manifestação cultural e o que costumavam fazer na hora de lazer.

Aliadas a essas informações, as tecnologias de informação e comunicação (TIC) foram incluídas como recurso metodológico no processo de construção das informações sobre as ocupações nas escolas no ano de 2016, principalmente quando identificamos os grupos formados nas redes sociais que abordaram os jovens e as ocupações dos espaços escolares. Tal fato refere-se à posição ocupada por tais ferramentas por proporcionar fácil comunicação e ser uma forma de legitimar as atividades realizadas pelos secundaristas.

Na sequência, com o objetivo de analisar a apropriação do espaço escolar pelos jovens após o processo de ocupação, foi realizado em outubro de 2017 um grupo focal com os estudantes envolvidos na ocupação. Entre os participantes, alguns já tinham concluído o ensino médio, e outros continuavam em sua trajetória escolar no Instituto. $\mathrm{O}$ contato deu-se por meio da rede de comunicação criada a partir da aproximação com os jovens na ocupação, possibilitando, assim, reuni-los em um dia específico para o reencontro com estes alunos e alunas e a execução de um diálogo sobre a ocupação, visando identificar o que ocorreu posteriormente a esse fenômeno e de que modo o movimento proporcionou um papel de mudança na escola. Essa etapa foi fundamental para a caracterização da relação dos alunos com a escola após o movimento de ocupação. 
Segundo Minayo (2000), o grupo focal tem como objetivo principal a obtenção de dados relacionados à pesquisa, logo o primeiro passo é estabelecer uma relação entre aqueles entrevistados e o pesquisador. A delimitação dos seus critérios é composta previamente pelo pesquisador, respeitando os objetivos gerais do estudo realizado. Essa técnica tem como base criar um espaço de discussão, fazendo com que os indivíduos manifestem suas percepções acerca daquele fenômeno investigado.

Assim, a abordagem para a análise do estudo que aqui se desenvolve tem como cunho principal o método qualitativo, sendo aquele utilizado para recolher e transcrever com maior possibilidade a dinâmica e os conflitos existentes no campo de desenvolvimento da pesquisa. Ou seja, se mostra numa tentativa de mensurar as subjetividades dos sujeitos envolvidos e seus conflitos, nos remetendo a uma análise que não pode ser resumida apenas à quantificação.

Este artigo está estruturado em quatro partes: esta introdução, na qual indicamos a origem do tema, perguntas, objetivos do trabalho, seguido por duas partes discursivas e, por fim, as considerações finais.

Na primeira parte, apresentamos a construção dos jovens como sujeito de direitos no percurso histórico dos movimentos sociais no Brasil, para juntamente com o movimento da "Primavera Secundarista" e com a associação ao momento de ocupações em todo território nacional, abordar a experiência do movimento de ocupação do Instituto Federal de Cabedelo por intermédio das vozes que participaram do movimento, e a posteriori, a sua relação com a escola.

Por fim, apresentamos as considerações finais, destacando os principais resultados alcançados com a pesquisa e as reflexões construídas ao longo do texto, dentre as quais torna-se perceptível uma maior quantidade de participação de alunos mais jovens, concentrados no primeiro ano, e, a partir dos relatos, demonstra-se uma mudança na relação com a escola por intermédio de uma maior apropriação do espaço escolar pelos alunos. 


\section{Movimentos sociais no Brasil: a juventude entra em cena}

O percurso histórico dos movimentos sociais foi responsável por causar mudanças nas estruturas sociais. As lutas no campo social fazem parte da história dos sujeitos podendo demarcar uma das características de um determinado grupo social. Por isso, deve ser compreendido que os movimentos podem carregar consigo aspectos identitários dos indivíduos, além de fornecem elementos para as mudanças das instituições sociais e, por consequência, às relações sociais.

De acordo com Gohn (2011), a concepção de mudanças sociais passa diretamente pela perspectiva dos movimentos sociais, principalmente no confronto com o poder hegemônico e os valores morais de cada período, nessa perspectiva a autora afirma:

Na realidade histórica, os movimentos sempre existiram, e cremos que sempre existirão. Isso porque representam forças sociais organizadas, aglutinam as pessoas não como força-tarefa de ordem numérica, mas como campo de atividades e experimentação social, e essas atividades são fontes geradoras de criatividade e inovações socioculturais (GOHN, 2011, p. 4).

Historicamente, os movimentos sociais exerceram essa função de manutenção das novas formas de organizações sociais, especialmente por seu caráter de contrapoder, ou seja, agindo como elemento autônomo e forte que contribui para a transformação social tanto de maneira formal, na efetivação de direitos, bem como nas relações sociais, incorporando os indivíduos nas decisões políticas (GOHN, 2011).

A juventude representa um grupo social que marca os processos de enfrentamento das questões que emergem socialmente e, diante disso, "a formação de novos agentes sociais representa, assim, sob o ponto de vista da preservação e transmissão do patrimônio cultural, uma garantia de continuidade e renovação" (FORACCHI, 1972, p. 22). Por isso, a categoria juventude, em sua construção histórico social, proporciona compreender como os fenômenos sociais são desenvolvidos e, principalmente como são materializados os processos de transformações sociais.

A rua, democraticamente, enquanto espaço público de contestação política, se constituiu como meio fundamental na concretude das grandes mobilizações da juventude brasileira. Esse canal histórico de luta se tornou uma das instâncias utilizadas pelos mais 
diversos grupos políticos, setores sociais e, inclusive, com pautas opostas. As contradições e simbioses que são características presentes na sociedade são atravessadas pelo contexto político e demonstram como esse espaço pode ser mutável e reconfigurado a partir dos atores sociais que por ela se manifestem:

No espaço público - nas esquinas ou nos parques, nas ruas durante as revoltas ou os comícios - , as organizações políticas podem representar a si mesmas para uma população maior e, através dessa representação, imprimir alguma força a seus gritos e demandas. Ao reclamar o espaço em público, ao criar espaços públicos, os próprios grupos sociais tornam-se públicos (MITCHELL, 2003, p. 12, tradução nossa).

A organização estudantil, como um dos meios pelos quais a juventude assume o papel de contestação diante da sociedade, percorreu diferentes caminhos e modos de organização ao longo da história brasileira. As nuances do processo histórico desses movimentos são reforçadas pela literatura com objetivo de classificar, de acordo com os critérios delimitados, os movimentos protagonizados pelos jovens.

Por isso, existe um esforço da literatura em subdividir a história do movimento estudantil em dois períodos distintos: o primeiro com a fundação da União Nacional dos Estudantes (UNE), no período de 1937, responsável pela organização dos estudantes a nível nacional; e o momento anterior, em 1934 quando são destacadas outras formas de organização dos estudantes de maneira local ou regional (POERNER, 2004).

Segundo Martins Filho (1986), as organizações feitas anteriormente à criação da UNE se constituíram como movimentos estudantis, mas não chegaram a construir uma identidade nacional. Porém existe uma divergência dentro dos estudos sobre movimentos sociais dos critérios classificatórios relativos aos movimentos estudantis.

Nesse sentido, Bringel (2009) defende um modo de enquadramento diferente, contrariando a literatura que reparte os movimentos estudantis em dois momentos singulares. Isto é, para o autor, por mais que os movimentos estudantis não contemplem os aspectos "clássicos" dos movimentos sociais, como certa estabilidade e identidade coletiva, as práticas experienciadas pelos movimentos estudantis anterior à criação da UNE apresentaram características fundamentais para serem considerados movimentos autênticos, principalmente pela organização, meios de ação e estratégias utilizadas. 
Assim sendo, a dualidade entre a repartição dos movimentos estudantis promovida pela literatura atravessa o percurso histórico brasileiro, demonstrando que pode ter existido um perfil híbrido da organização dos movimentos estudantis. Isso posto, se a maneira inicial de organização estudantil teve como marco as mobilizações regionais, e passou em determinado momento para atuação de maneira institucionalizada nacionalmente, hoje entram em contraste por agirem simultaneamente sob as configurações dos movimentos estudantis anteriores, ao passo que prezam pela busca pela autonomia e pelos novos meios de organização.

Esses processos de transformações nos modos de organização presentes nos movimentos estudantis são de fato importantes para se atentar em relação às semelhanças e descontinuidades nos movimentos estudantis do Brasil. Por isso, analisar os marcos históricos das lutas estudantis se torna fundamental para compreender como se materializam as configurações das manifestações protagonizadas pelos estudantes na contemporaneidade.

Entretanto os secundaristas se organizaram nacionalmente somente em 1948 quando aconteceu o $1^{\circ}$ Congresso Nacional dos Estudantes Secundaristas que teve como destaque a criação da União Nacional dos Estudantes Secundaristas - UNES. Somente no segundo Congresso, em 1949, transformou o nome para União Brasileira dos Estudantes Secundaristas - UBES (CINTRA; MARQUES, 2009).

Para os secundaristas, após os entraves promovidos pela história, principalmente em seguida ao período do Golpe Militar (1964), o processo de construção das entidades nacionais e regionais tem como marco importante a concretização do direito à organização de grêmios livres, na lei $\mathrm{n}^{\circ} 7.398$, aprovada somente em 4 de novembro de 1985 (GONZÁLEZ et al, 2009).

Durante a Ditadura Militar (1964-1985), as leis de repressão levaram os movimentos estudantis à ilegalidade. $\mathrm{O}$ uso dos mecanismos de violência marca esse período da história brasileira, e um dos símbolos da repressão em relação aos movimentos estudantis foi a morte do secundarista Edson Luís, alvejado por tiros durante uma manifestação estudantil no Rio de Janeiro cujo cortejo fúnebre teve grande comoção pública. 
Nesse momento da história brasileira, conhecida como "anos de chumbo", o nível de acirramento político perpassava as instâncias legais, por isso, uma parte desses jovens se incorporou a outras formas de resistência, a exemplo, a luta armada

A organização estudantil resistiu por anos ao Regime Militar (1964) na clandestinidade. Porém ao se retomar o movimento estudantil institucionalizado, particularmente com a reorganização da União Nacional dos Estudantes, o contexto de insatisfação estudantil com o governo que devido as crises financeiras nas universidades, representou um agravamento dos protestos deste período (COELHO, 2006).

No ano de 1979, aconteceu o primeiro encontro nacional de estudantes após a Ditadura Militar (1964), denominado como "Congresso de Reconstrução” em Salvador, Bahia. Entre os temas formulados, sem dúvidas, o principal era o debate sobre o estatuto e carta de princípios que foi amplamente aceita pelos estudantes. Com isso, o movimento reelabora suas demandas e prioriza aspectos como: a gratuidade do ensino público, a anistia a todos, e, principalmente, por uma assembleia nacional constituinte (COELHO, 1990).

Nesse sentido, foi durante os anos de 1990 que a visibilidade social dos jovens se acentuou, a participação nas ruas engendrando ações individuais e coletivas são evidências desse período. Segundo Sposito (2000, p. 79), a partir dos anos 1990, os jovens "mostraram um alargamento de seus interesses e práticas coletivas, acentuando a importância da esfera cultural que fomenta mecanismo de aglutinação de sociabilidades".

A reorganização dos movimentos estudantis presentes no processo de redemocratização, iniciado em 1979, fortaleceu a campanha das "Diretas já" em 1984, ganhando aderência da população e aglutinando forças a diversos segmentos sociais. No decorrer do processo histórico, as ruas foram tomadas novamente pelos estudantes com o movimento "Os Caras-pintadas" protagonizando uma das maiores mobilizações desse período, contribuindo para a implementação do impeachment do Presidente Fernando Collor de Mello no ano de 1992.

Nesse sentido, como afirma Gohn (2014), os movimentos sociais passam a incorporar elementos burocráticos como forma de se institucionalizarem. Destacando que nesse momento se percebe a abertura de um espaço de luta além das ruas, ou seja, no 
campo da política, dos fóruns e das políticas públicas, mobilizando bases para a participação popular institucionalizada, reafirmada pela Constituição de 1988.

A escola surge como um espaço de interações afetivas e simbólicas, principalmente por se relacionarem com o contexto social em que vivem, no bairro, podendo se tornar uma forma de integração dos indivíduos com as demandas de cada realidade social e de políticas públicas que os contemplam. Nesse sentido, a dimensão do jovem na sociedade é construída pela sua interação com o meio social, por isso a necessidade de políticas públicas nacionais que contemplem as demandas deste segmento social (PAIS, 1993).

A partir da organização da juventude na $1^{\text {a }}$ Semana de Juventude em 2003, contando com a participação dos jovens e representação de diversos estados, com o Relatório Preliminar foi possível prosseguir com a elaboração do Plano Nacional da Juventude que tinha como base as propostas para o desenvolvimento de um projeto de lei voltado para esse segmento.

O Plano Nacional de Juventude, por meio da Lei $\mathrm{n}^{\mathrm{o}} 4.530$ de 2004, aponta as necessidades para integrar a juventude ao desenvolvimento do país, dentre elas, abrir canais de diálogos para as representações juvenis, criação de políticas em diversas áreas da sociedade, como a educação, ciência e tecnologias, saúde e distribuição de renda. Para isso, o plano tem como objetivos:

- Incorporar integralmente os jovens ao desenvolvimento do país, por meio de uma política nacional de juventude voltada aos aspectos humanos, sociais, culturais, educacionais, econômicos, desportivos, religiosos e familiares;

- Construir espaços de diálogo e convivência plural, tolerantes e equitativos, entre as diferentes representações juvenis;

- Criar políticas universalistas, que tratem do jovem como pessoa e membro da coletividade, com todas as singularidades que se entrelaçam. (BRASIL, 2004, p. 4)

No ano de 2005, foi criada a Secretaria Nacional de Juventude e o Conselho Nacional de Juventude (CONJUV), que foram instituídos a partir da lei ordinária 11.129 de 30 de junho, marcando os processos para conquistar os espaços para esses jovens (CALIARI; HELMER, 2006). 
A organização dos jovens possui marcos históricos na concretude de direitos. Porém o processo de transformação do movimento estudantil, como dito, pôde permanecer em contínua dualidade e contradições ao analisar suas implicações no tempo histórico, e consequentemente as mudanças nas formas de organização e atuação. Por isso, o movimento dos estudantes voltou à cena em 2007 e 2008 com as ocupações de reitorias, materializando processos de continuidades e rupturas nos movimentos estudantis do Brasil (BRINGEL, 2009).

Nesse momento, os movimentos estudantis anunciam aspectos que se concretizam nos movimentos futuros, e representaram críticas aos movimentos da época. Isto por terem como ponto de interseção aspectos como: as assembleias de organização e deliberação; a crítica aos canais institucionais da política; os ataques recebidos dos meios de comunicação hegemônicos; a incapacidade dos governantes de interpretar os acontecimentos das ações estudantis. São algumas das caraterísticas que marcam tal movimento, além disso, Bringel (2009, p.112) aponta:

- Maior democratização da informação e da comunicação: os blogs foram utilizados pela primeira vez nas ações coletivas; servindo de ferramenta mais aberta e direta de comunicação; para divulgação;

- Maior horizontalidade na deliberação: maior protagonismo das assembleias em detrimento dos comitês fechados e órgão de representação;

- $\quad$ Ausência de um líder definido. Os estudantes alternavam-se nessa função.

Porém, segundo Bringel (2009), esse conflito permanece no renascer das novas mobilizações estudantis, contribuindo para a permanência da dualidade entre elementos do passado com tendências que apontam para o seu futuro. Nesse sentido, podemos vislumbrar que os movimentos estudantis brasileiros que vieram a se desenvolver permanecem com um período de transição ou apontam para coexistirem aspectos do passado com elementos do futuro.

Deve ser lembrado que a criação desses espaços de diálogos parte de um grande esforço desses jovens em construírem e legitimarem seu lugar no destino do país. Isto é, os anos de lutas e mobilizações da juventude brasileira concretizaram uma voz que precisava ser ouvida e firmando-se como um grupo social que contesta. 
A aprovação do Estatuto da Juventude, a Lei 12.852 de 05 de agosto de 2013 (BRASIL, 2013), representou a compilação de direitos destinados à juventude. A conquista perceptível, por meio do processo paulatino de resistência e a luta por efetivação dos direitos políticos e sociais, coloca em evidência a necessidade de elaboração e promoção de políticas públicas para promover as pautas da juventude.

O Estatuto da Juventude conta com artigos direcionados à educação, saúde, cultura, ao território e promove uma ampla abertura para o debate sobre os jovens. Nas diretrizes, cita os principais canais para ampliação da participação juvenil nos diversos espaços sociais ao incentivar a conquista da autonomia dos jovens e colaborar para sua valorização enquanto sujeito de direito, como aponta:

Art. $2^{\circ} \mathrm{O}$ disposto nesta Lei e as políticas públicas de juventude são regidos pelos seguintes princípios:

I - Promoção da autonomia e emancipação dos jovens;

II - Valorização e promoção da participação social e política, de forma direta e por meio de suas representações;

III - Promoção da criatividade e da participação no desenvolvimento do país; IV - Reconhecimento do jovem como sujeito de direitos universais, geracionais e singulares (BRASIL, 2007, p. 26).

Nesse sentido, o estímulo da participação dos jovens na política serve como base para todos os direitos posteriores. Logo, sendo possível afirmar que com a participação da juventude nas decisões políticas pode ocorrer a concretização dos seus direitos. Nesse sentido, segundo o estatuto, as políticas públicas de juventude devem ser formuladas e articuladas em conjunto entre os 3 entes federados, ou seja, passando pela União, o Estado e o Município, conforme figura 1: 
Figura 1: Formação e articulação das políticas da juventude

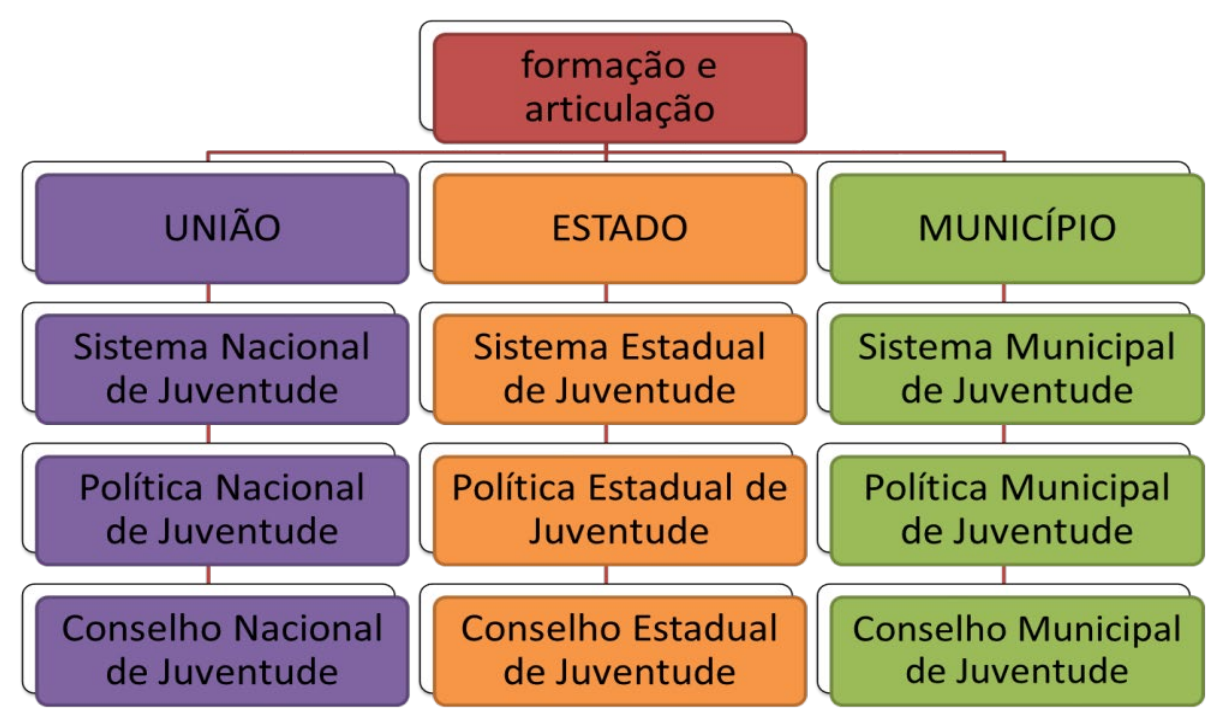

Fonte: MEDEIROS, 2016.

A concepção do jovem como um sujeito de direitos foi introduzida um pouco antes com a fundação da Secretaria Nacional da Juventude (SNJ) no ano de 2005. Portanto consequência direta das conferências voltadas para as questões da juventude realizadas em 2008, em 2011 e, posteriormente a de 2015, as quais geraram a compilação de documentos que serviram de base para a compreensão das demandas juvenis.

Mas cabe salientar a dificuldade existente no número de conselhos de juventude em estados e municípios como aponta a $3^{\mathrm{a}}$ Conferência Nacional da Juventude. Isto é, persiste uma quantidade de municípios que ainda não possuem um espaço destinado ao acolhimento de jovens para funcionar de maneira plena os programas de políticas públicas para a juventude. Entretanto, por mais que existam avanços enquanto sujeito de direito, os indicadores apontam sobre o distanciamento da participação da juventude institucional para outras esferas.

A pesquisa realizada no ano de 2013 pelo "Participatório - Observatório Participativo da Juventude", vinculado à Secretaria Nacional de Juventude, teve como objetivo traçar o perfil dos jovens, como também compreender os temas que faziam parte do seu contexto. O estudo apontou que as formas de atuação, segundo a maioria dos jovens, acreditam que podem mudar a realidade social de seu país por intermédio da 
participação em mobilizações de rua e outras ações diretas (45); atuação em associação ou coletivos que se organizam por alguma coisa (44), como aponta o gráfico 1

\section{Gráfico 1: Formas de atuação que podem melhorar as coisas no Brasil}

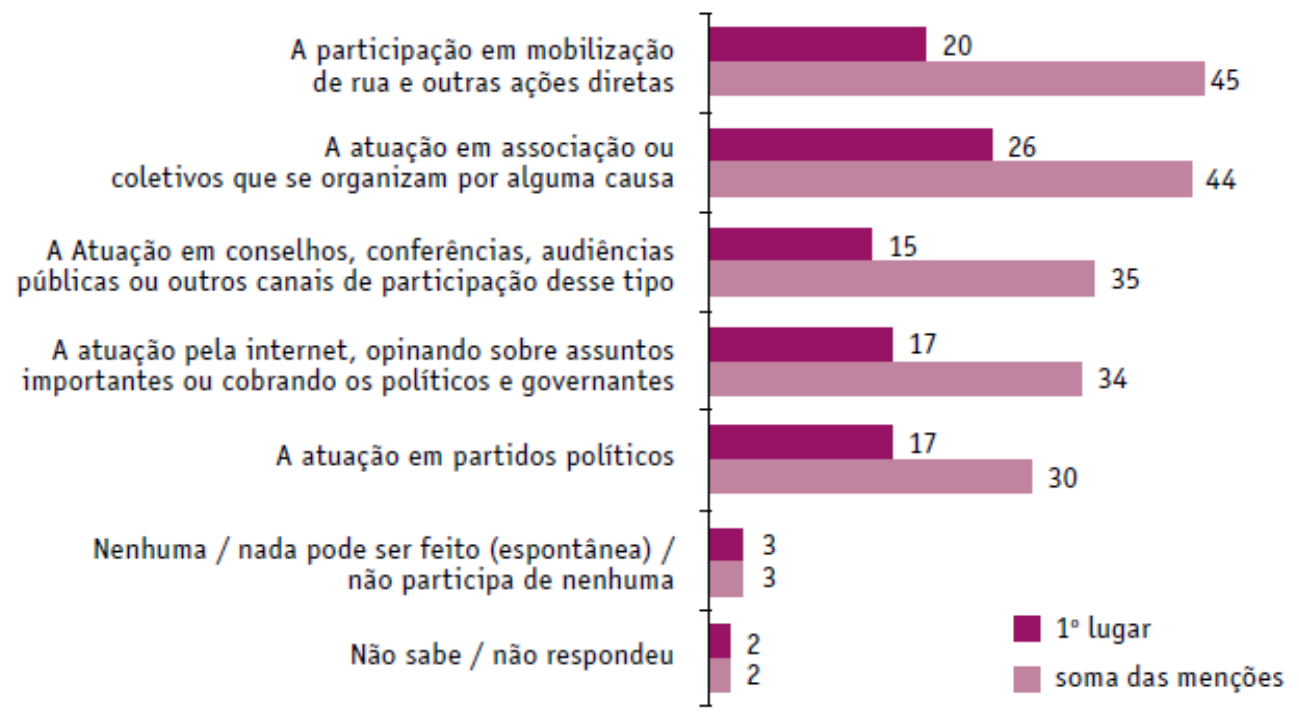

Fonte: Agenda Juventude Brasil, 2013, p. 37.

Nesse sentido, a busca pela incorporação dos direitos da juventude, como também a sua maior participação, como sinalizam os documentos oficiais, passam diretamente pelas organizações dos movimentos sociais. Nessa perspectiva, perceber os jovens inseridos nesse contexto faz parte da sua busca por autonomia e por mudança social da sua realidade a partir de uma maior participação nas decisões políticas nacionais.

Isto é, as formas institucionais de organização começaram a ser questionadas buscando caminhos alternativos para a luta política, ou pelo menos, indicam um novo tipo de necessidade de organização. Por isso, as pressões sociais por participação nas decisões políticas sinalizavam para necessidade de mudança no processo de tomada de decisões como afirma Gohn:

[...] As manifestações são movimentos que construíram significados novos para as lutas sociais (esse sim, uma categoria mais ampla). E construíram esses novos significados porque novos sujeitos entraram em cena, com práticas diferenciadas, valores, formas de ação e procedimento discursivos (2014, p. 435). 
As jornadas de junho de 2013 inauguram um novo ciclo de lutas dos movimentos sociais no Brasil, que vão ser observados nas Ocupações das Escolas em São Paulo no ano de 2015, e em todo país no ano seguinte, ao mesmo tempo que chocam com as dinâmicas anteriores de organização estudantil — institucionalizadas e hierárquicas —, se aproximam das lutas de outros movimentos sociais globais e na América Latina, que emergem no século XXI (MENDES, 2017).

Desse modo, segundo Castells (1999), as Tecnologias de Informação e Comunicação (TIC) fazem parte dos elementos dos novos movimentos sociais contemporâneos, além disso, identifica que as características compostas por esses movimentos são representadas por sua organização autônoma e a formação de uma rede de comunicação mundial. Por isso, conseguem romper paradigmas em relação à forma de organização e associarem de maneira singular na atualidade, principalmente por meio do ciberespaço, como afirma:

\footnotetext{
Os espaços ocupados têm desempenhado um papel importante na história da mudança social, assim como na prática contemporânea eles criam uma comunidade, e a comunidade se baseia na proximidade. Proximidade é um mecanismo para superar o medo. Logo, superar o medo é um estágio necessário para os indivíduos se envolverem num movimento social. (CASTELLS, 2013, p. 15).
}

Por isso, essas ações relacionadas, rua e/ou espaço virtual demonstram a capacidade de diferenciação com os movimentos sociais tradicionais e inauguram, dentro da literatura, um novo processo analítico, nos quais as formas de organização características da contemporaneidade, como a utilização do ciberespaço como instrumento de comunicação, criam novas formas de sociabilidades e autonomia, demonstrando um novo caminho para a participação popular e construção das relações sociais.

\section{OCUPA IF CABEDELO: "se prepare que o pavio vai acender"}

Tempos Insanos

"Pois se prepare então que o pavio vai ascender povo resistente, força que não se acaba, luta pra viver e não se cala, se cala, se cala. Espírito combatente, guerreiros do terceiro mundo, sobrevivente no suor e na raça, além da alienação, além dessa trapaça. 


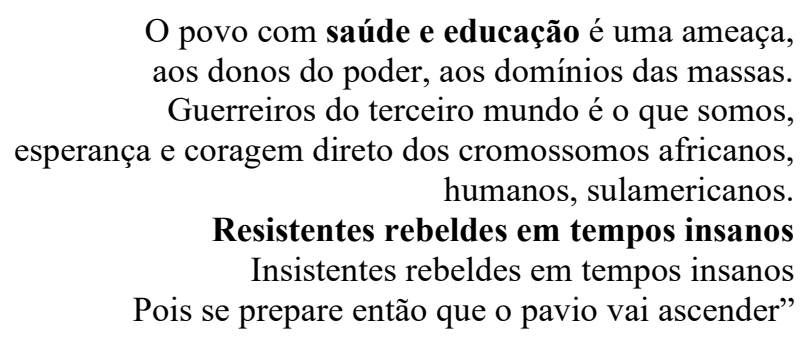

Por Mega Bo feat. BNegão (2016)

Os versos apresentados fazem parte do enredo do primeiro vídeo de divulgação do "OCUPA IF CABEDELO" 1, como plano de fundo, o compilado de imagens que retratam os jovens se organizando naquele espaço. O protagonismo da juventude retratado nesses pequenos fragmentos representa apenas uma parte da realidade vivida por esses estudantes. O impacto das suas ações moveu os aspectos políticos do país, a dinâmica educacional, e, consequentemente suas experiências com a escola. Nesse contexto, os estudantes foram propulsores fundamentais para o processo de resistência, se tornaram "resistentes em tempos insanos".

O Instituto Federal de Educação, Ciência e Tecnologia da Paraíba (IFPB), campus Cabedelo, está localizado na Grande João Pessoa, na rua Santa Rita de Cássia, nº 1900 , Bairro de Jardim Camboinha, e em 2016, dentre os cursos técnicos integrados ao ensino médio estavam: Recursos Pesqueiros; Meio Ambiente; Design Gráfico e Ciências Biológicas, e cursos de modalidade de educação à distância como: Técnico de Segurança no Trabalho e Secretaria Escolar.

No ano de 2016, o Instituto Federal da Paraíba, campus Cabedelo, emergiu como campo de pesquisa por se tornar uma das primeiras escolas da região da Paraíba a se organizarem diante desse contexto político e deflagraram a ocupação.

A trajetória histórica dos estudantes no Instituto possui um passado de luta e resistência. O funcionamento que antes era situado numa sede provisória, no centro de Cabedelo/PB, com a infraestrutura inadequada para a realização das atividades educacionais previstas para os alunos, foi o primeiro desafio que eles encontraram para

\footnotetext{
${ }^{1}$ Disponível em: https://www.youtube.com/watch?v=UTTpbCQQM2c\&ab_channel=OcupaIFPB
} 
reivindicar a apropriação da nova sede que estava concluída e apta às exigências previstas para o ensino (MENDES, 2017).

A organização entre os estudantes do ensino médio técnico, superior e subsequente, obteve êxito na apropriação do novo local em outubro de 2013 (MENDES, 2017). A conquista desse novo espaço tem como manifestação a organização dos estudantes para o fechamento das principais rodovias da cidade como forma de protesto.

Nesse processo, constituindo-se as primeiras turmas a se formarem pelo Instituto, a luta por um espaço físico adequado é um marco desses alunos. A juventude que permaneceu no campus de Cabedelo se caracteriza pela preocupação com o espaço ocupado, por isso, a história que os estudantes têm com o Instituto sinalizam para o entendimento do processo de organização dos estudantes nesse local (MENDES, 2017).

A dificuldade com a acessibilidade à nova sede continuou a ser uma questão latente para os estudantes. Por isso, as implicações da nova localização do Instituto vieram a se tornar tema para Farias (2016), em seu trabalho realizado para conclusão de curso integrado em Meio Ambiente. A autora reafirma a afinidade dos estudantes em relação ao espaço educacional:

\begin{abstract}
$\mathrm{Na}$ organização espacial das cidades brasileiras é verificada a existência de uma grande segregação espacial urbana. As classes sociais que ficam concentradas em determinadas regiões ou bairros de uma cidade, principalmente em locais onde há uma grande diferença de renda entre os grupos [...] A partir da linha férrea até o manguezal encontramos a área ocupada pela classe menos favorecida de todas que apresenta vários problemas, como a falta de saneamento básico, ruas sem pavimentação, muita sujeira e crianças brincando em locais inadequados devido à falta de um espaço público com segurança para elas (FARIAS, 2016, p.18).
\end{abstract}

Nesse processo histórico de luta, emergiu um projeto de extensão formado por alguns desses jovens, o "Núcleo de Teatro do Oprimido do IFPB Cabedelo - NTO", um grupo teatral que foi responsável por promover debates de cunho político e educacional naquele espaço. A união dos estudantes por meio das manifestações históricas e culturais se tornou essencial para organização da ocupação no ano de 2016.

Por meio da iniciativa do professor de geografia e do psicólogo do Instituto Federal da Paraíba, campus Cabedelo, a formação de um grupo de Teatro, baseado no 
método teatral intitulado "Teatro do Oprimido" (T.O.), promoveram debates de cunho político e educacional naquele espaço como afirma a pesquisadora e integrante do grupo:

O T.O é uma técnica político-teatral desenvolvida por Augusto Boal que tem o intuito de trazer os problemas enfrentados pelas diversas comunidades para o campo da encenação, quando pessoas comuns se tornam atores e entram em cena, buscando desenvolver os conflitos postos. Pela sua versatilidade, o T.O vem sendo utilizado em diversos ambientes e situações de opressão que vão desde movimentos sociais até grupos menores, como aqueles localizados em escolas. Nesse trabalho, o T.O., enquanto arte e política, se une à educação e à juventude, a partir do entendimento de que a educação é formadora de cidadãos e o período escolar é fundamental na formação pessoal dos estudantes (DIAS, 2019, p. 21).

O processo de organização dos estudantes através do T.O. configurou-se fundamental no desenvolvimento do movimento de ocupação em 2016, visto que durante a pesquisa realizada, a maioria dos ocupantes participava dessa manifestação cultural, o grupo teatral denominado "Núcleo de Teatro do Oprimido (NTO)".

A pesquisa realizada por Dias e colaboradores $(2017$, p. 8$)$, durante o mês de novembro de 2016, “objetivou traçar o perfil socioeconômico e cultural de seus participantes". Com as devidas ressalvas, existia uma alternância de pessoas durante toda a semana e turnos, com a quantidade de 150 a 300 pessoas durante todo período da ocupação, segundo as informações prestada pelos estudantes no estudo.

O perfil dos estudantes que participaram da ocupação foi composto por jovens com idade entre 15 a 19 anos e, predominantemente com a idade de 16 anos (47\%), ou seja, alunos que na grande maioria faziam parte dos primeiros anos do ensino médio. Na divisão por sexo, foi verificado que existia uma proximidade quanto ao número de participação, por mais que durante a pesquisa a quantidade de meninos tenha se sobressaído (59\%), foi possível constatar, por outro lado, que as meninas participavam ativamente na coordenação e articulação do movimento. Vejamos algumas dessas informações nos gráficos 01 e 02 : 
Gráficos 01 e 02: Idade e sexo dos jovens que ocuparam o IF Cabedelo/2016

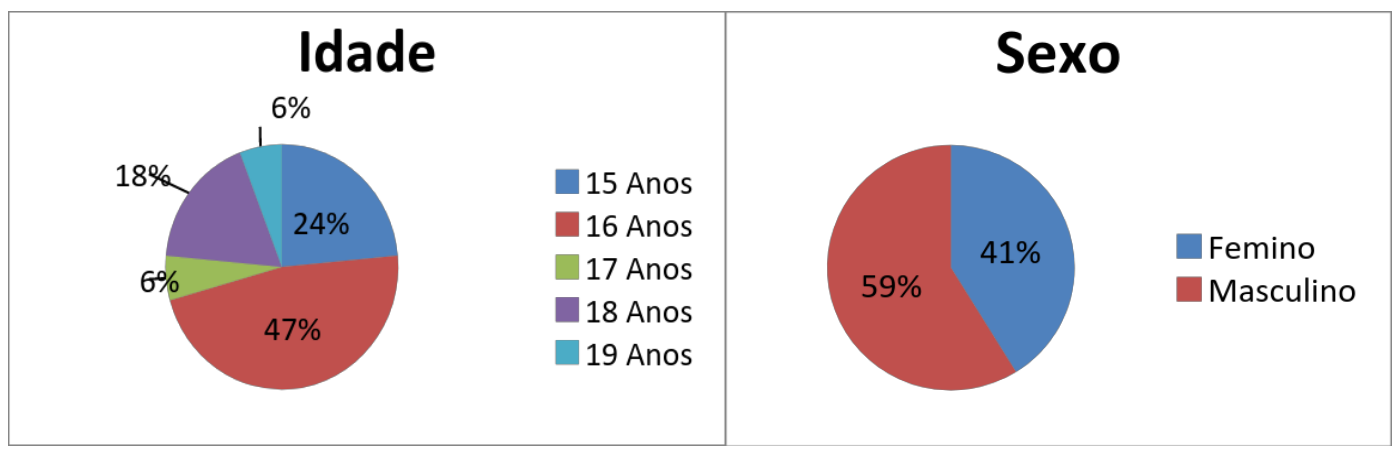

Fonte: Dias e colaboradores (2017, p. 9)

Com relação à escolaridade dos pais, constatamos que a maioria pertence ao grupo dos que estão entre os que concluíram o ensino médio e aqueles que possuíam o nível superior completo ou incompleto, formando a maioria dos entrevistados. Nesse sentido, demonstra as construções do círculo familiar sinalizando para uma família com acesso à educação.

A pesquisa ainda apontou que, para os alunos, a história de luta da escola se revelou fundamental. Por isso, a importância da criação do grupo de teatro como forma de organização e manifestação cultural foi essencial para os jovens explorarem o seu tempo em diversos aspectos, com a música e a leitura.

Segundo Mendes (2019, p. 8), durante os "52 dias ocupando o espaço do campus os estudantes tinham uma rotina para as diversas atividades educacionais". A divisão dos horários consistia em turnos para dormir e acordar conhecidos como "toque de recolher" e "alvorada", como também o tempo destinado para alimentação, oficinas e debates alternados durante manhã e tarde. O horário noturno era reservado para as apresentações culturais, como música e exibição de filmes e roda de conversas.

A sistematização das assembleias contava com a participação majoritária dos alunos, podendo ter a presença de professores e apoiadores do movimento como forma de auxiliar em demandas externas e compor as atividades como oficinas e aulas, mas só os alunos do IF tinham poder de voto. Isto é, existia um grupo de discussões das questões 
organizacionais, mas a votação e encaminhamentos eram feitos apenas por alunos da escola.

Nesse sentido, a horizontalidade no processo de organização do movimento de ocupação - em que nenhuma figura se colocava como representante ou líder do movimento - , se tornou fundamental para a configuração das comissões. Além da participação dos processos decisórios como assembleias, a dinâmica dos afazeres básicos de convivência e administração, como limpeza, alimentação, vigilância, fiscais, comunicação, divulgação, negociação e planejamento das atividades e rotinas diárias, era responsabilidade de todos.

Por isso ressaltamos ainda o cunho educativo, político e produtivo das atividades promovidas pelo movimento, como realizar debates com temáticas sobre as razões do movimento, sobre machismo, racismo, homofobia, questionamentos, problemas sociais etc. As oficinas eram voltadas para a valorização das artes manuais e corporais, produção de cartazes, customização, reciclagem, dança, teatro, música etc. Essas atividades eram abertas ao público, o que ajudava na aproximação dos moradores locais, contando assim com a participação da comunidade ao redor.

A segunda fase da pesquisa se tornou indispensável para compreendermos como os jovens percebem o espaço escolar após o processo de ocupação da escola. A partir do grupo focal, compreendeu-se que a vivência na ocupação reverberou de maneira significativa nas suas trajetórias pessoal e política.

Nesse sentido, o movimento de ocupação representou uma ruptura nos moldes de fazer e praticar política, bem como um corte geracional para os estudantes. Segundo os alunos, o movimento de ocupação foi seu primeiro contato com algum tipo de movimento social na sua geração, se tornando um catalisador para a permanência no ensino, tanto que a maioria dos ocupantes ingressou em cursos superiores. A partir dos relatos, a aproximação com os espaços organizados e de decisões se tornou mais recorrente, segundo um dos alunos:

A ocupação foi um espaço que deu voz aos alunos que eram do campus e não participavam das discussões, como também deu voz às pessoas da comunidade 
que está próxima do campus. Muitas pessoas que não eram estudantes vinham para cá apoiar, participar das oficinas, das aulas (informação verbal). ${ }^{2}$

Durante a ocupação, um dos pontos destacado foi a união dos alunos de todos os níveis do campus. No discurso dos jovens, foi possível identificar aspectos como a união entre os estudantes, que por mais que tenham passado por processos difíceis de repressão, conseguiram instaurar o espírito de coletividade (MENDES, 2019). Nesse sentido, a relação de coletividade era fundamental para o desenvolvimento do movimento de ocupação, como afirma:

Foi dureza, mas foi maravilhoso. Foi uma das maiores uniões que eu vi aqui no IF de alunos, junto com alguns professores, apesar de outros não aceitarem, outros vinham e sempre ajudavam, sempre tinha alguém que chegava e trazia comida, ou ajudar nas palestras. Era uma coisa muito bonita de se vê. Mas meus pais não aceitaram muito, principalmente influenciados pelos que estavam vendo na televisão. Com a visão muito distorcida, achando que só participavam vagabundos, que o pessoal vinha para se drogar. E na realidade muitas pessoas aprenderam aqui o sentido de coletividade, de união, a respeitar o espaço, deixar limpo, fazer comida. A minha participação foi motivada não só pela participação do TO, mas como um todo. Desde que entrei no IF eu venho mudando, antes eu não me interessava por essas questões. Eu achava que não tinha força, e minha força veio dessas coisas, do IF, do TO, das pessoas. E em questão das mudanças nas escolas, eu vejo que tem mais um espírito de união das pessoas (informação verbal). ${ }^{3}$

Como Dayrell e Reis (2007) revelam, um dos critérios para a condição juvenil é a sociabilidade, sendo o processo de socialização na escola um dos mais importantes na trajetória dos jovens, pois é entrando em contato com o outro que cria um "eu" e um "nós" distintivos. "A turma de amigos" que se forma nesse contexto da escola, se torna uma referência clara na trajetória desses sujeitos, é com eles que conversam, que convivem e trocam experiência. A fala acima de nosso “ocupante”, reafirma a análise desses autores, ao destacar o crescimento do espírito coletivo dos estudantes durante a ocupação.

Além dos atores do processo da ocupação, as plataformas online de informação serviram como armazenamento, construindo parte dos fios condutores que permanecem como fonte permanente de acesso ao fenômeno. Por isso, ao observar a reação dos

\footnotetext{
${ }^{2}$ Relato fornecido por secundaristas do Instituto Federal da Paraíba (IFPB), campus Cabedelo, por meio do grupo focal realizado em outubro de 2017. Também apresentado por Mendes (2017, p. 54).

${ }^{3}$ Relato fornecido por secundaristas do Instituto Federal da Paraíba (IFPB), campus Cabedelo, por meio do grupo focal realizado em outubro de 2017. Também apresentado por Mendes (2017, p. 56)
} 
grandes veículos de comunicação a esse momento, os estudantes da ocupação evidenciaram como consequência as novas formas de comunicação democráticas que foram utilizadas pelos grupos nas redes sociais, como explica um dos nossos informantes:

Logo, a gente passou a vê o IF como nosso de verdade, passou a reivindicar quando a gente acha necessário, as pessoas que participaram passaram a compartilhar mais fatos da realidade política nacional. E isso é fruto também dos professores, foi a partir da iniciativa de buscar o debate em sala de aula, de questionar sobre a realidade social em que vivemos, é a partir dessas ações que podemos pensar criticamente (informação verbal). ${ }^{4}$

As grandes mídias reintegravam o caráter ostensivo que as ocupações supostamente desempenhariam, reforçando uma pressão social em termos de desqualificação ou estratégia de desgaste em relação à ocupação, utilizando recursos como a pressão social por datas marcantes, como as eleições municipais em 2016 e a prova do Exame Nacional do Ensino Médio (Enem), evidenciando o impasse das manifestações e a necessidade do espaço.

Recordamos Ianni (1963) quando admite que por mais que aconteça um interesse em transformar o termo "jovem radical" — utilizado para definir a juventude como comportamentos desordeiros - o autor afirma que as manifestações juvenis podem se caracterizar na esfera da vida política, ou seja, os comportamentos e manifestações juvenis socialmente definidos como radicais possam ser interpretados do ponto de vista político.

A fórmula educativa de participação da juventude no processo de ocupação das escolas evidencia a necessidade de participação dos jovens nas decisões políticas (MENDES, 2019). Por isso, provocaram mudanças na relação dos estudantes com a escola como relata a informante:

No geral mudou o que é o IF, pois antes a gente sabia que o IF era um lugar que a gente tinha voz, no máximo, hoje a gente sabe que é um lugar em que a gente pode transformar, demonstrado com a ocupação, que foi um espaço democrático, envolvendo a política estudantil, política nacional, para construir

\footnotetext{
${ }^{4}$ Relato fornecido por secundaristas do Instituto Federal da Paraíba (IFPB), campus Cabedelo, por meio do grupo focal realizado em outubro de 2017. Também apresentado por Mendes (2017, p. 58).
} 
uma concepção de sociedade e de cidadania, então o IF é assim hoje por causa da ocupação (informação verbal). ${ }^{5}$

Para Morin (2010), o ensino educativo não se deve apenas ao saber, mas também um espaço que deva permitir compreender as condições dos sujeitos e auxilie a construir um pensamento liberto e crítico. Nesse sentido, a escola tem um papel fundamental na formação desses sujeitos, pois "a finalidade de nossa escola é ensinar a repensar o pensamento, a ‘des-saber' o sabido e a duvidar de sua própria dúvida” (MORIN, 2010, p. 2).

No processo de reflexão acerca do que foi a ocupação, os estudantes chegam à percepção de que o momento pelo qual eles passaram serviu como um dos caminhos para entenderem a realidade social em que estão inseridos. Ou seja, mais do que os conteúdos programáticos em sala de aula, a ocupação trouxe para os jovens uma maior sensibilidade para a leitura da realidade social, como também ampliou a compreensão do contexto político nacional, segundo relato:

Existe uma diferença de quando a gente aprende uma coisa agora e esquece, ou leva na brincadeira, ou isso é chato e outra coisa é quando você enxerga algo como seu direito. $\mathrm{O}$ direito de que você tem de atuar. O direito que você tem de entender aquilo que você está vivendo, o porquê de a escola ser assim, o porquê de não ter um teto. Durante a ocupação foi possível entender o que é o golpe, o que é a reforma do ensino médio, o que é a escola sem partido. E a gente levar tudo isso como uma coisa chata, uma coisa sem importância, resulta nisso: numa escola sem partido, numa censura ao que é nosso. É a partir daí que nós, os jovens, começamos a entender. E partir daí que muitos jovens começaram a entender a realidade do país (informação verbal). ${ }^{6}$

O movimento de ocupação das escolas proporciona a ressignificação das relações estabelecidas no espaço escolar, principalmente quando rompe a hierarquização das posições sociais desses jovens enquanto apenas expectadores do conhecimento (MENDES, 2019). Nesse processo de transformação por parte dos jovens, com a possibilidade de decisão sobre as pautas e demandas, construiu-se, assim, novas maneiras desse indivíduo transmitir e se sociabilizar na sociedade. O livro "Escolas de luta" expressa um aspecto inovador deste movimento, confirmando que "as ocupações,

\footnotetext{
${ }^{5}$ Relato fornecido por secundaristas do Instituto Federal da Paraíba (IFPB), campus Cabedelo, por meio do grupo focal realizado em outubro de 2017. Também apresentado por Mendes (2017, p. 57).

${ }^{6}$ Relato fornecido por secundaristas do Instituto Federal da Paraíba (IFPB), campus Cabedelo, por meio do grupo focal realizado em outubro de 2017. Também apresentado por Mendes (2017, p. 59).
} 
geraram uma dinâmica de organização coletiva que forjou novas relações sociais", como afirmam Campos e colaboradores (2016, p. 13).

A dinâmica estabelecida nas ocupações das escolas em 2016 sinalizou outras possibilidades de organização dos movimentos sociais e, consequentemente das relações sociais, neste caso, estudantis. Nessa nova concepção, retirando as estruturas hierárquicas e estabelecendo a comunicação como pública comum a todos, como propõem Groppo e Silva (2020, p. 417):

\begin{abstract}
A experiência da ocupação teve grande impacto subjetivo sobre as e os ocupas. Ela suscitou intensos aprendizados políticos e processos de transformação de si. Como se viu, a subjetivação política se deu durante a ação coletiva que, por meio da desidentificação em relação a papéis heterônomos e subalternos, constituiu, com diferentes graus de efetividade, um coletivo de pessoas que se viam e agiam como iguais, a despeito de sua diversidade de condições e papéis sociais prévios.
\end{abstract}

Essa abertura no espaço temporal proporcionada pelos movimentos de ocupação, mesmo que seja no curto espaço de tempo, propõe uma nova forma de organização e participação social desses jovens. Por isso, no contraponto com os mecanismos convencionais utilizados como protestos e marchas, os campos de ocupação articulam-se nos espaços públicos com o objetivo de se apropriarem tanto quanto for possível, resistindo e insistindo no direito à criação de "novos mundos" (MENDES, 2019).

\title{
4 Considerações finais
}

O ano de 2016 compõe um novo ponto de inflexão nas lutas estudantis brasileiras. A denominada "Primavera Secundarista" representou a renovação dos ciclos do movimento estudantil, principalmente questionando as dinâmicas organizativas e mobilizadoras com a implementação de horizonte das relações e a ausência de lideranças definidas.

O Instituto Federal de Educação, Ciência e Tecnologia da Paraíba (IFPB), campus Cabedelo, emergiu como campo de pesquisa durante o movimento de ocupação em 2016, por seu papel de luta e resistência ao contexto nacional, e por possuir uma trajetória 
histórica de atuação dos estudantes em relação à defesa do espaço escolar como um direito.

Durante os 52 dias que ocuparam o espaço do campus, os estudantes reinventaram suas rotinas escolares. Os jovens implementaram, por meio da autonomia que se revelavam durante às assembleias, na divisão de tarefas, na organização das oficinas, um contraponto das relações hierarquizadas empregadas na estrutura escolar.

O “OCUPA IF CABEDELO" se integrou ao movimento de ocupação em 2016 nacionalmente, inaugurando uma conexão com os estudantes no país todo, por intermédio das novas formas de comunicação e interação com os indivíduos, por meio de uma pauta, revelando elementos próprios de cada movimento. A evidência, nesse sentido, são os retratos da mudança, e acontece na reestruturação, na organização dos estudantes, principalmente no que diz respeito às formas de organização e deliberação.

A divisão de tarefas foi um aspecto interessante relatado sobre as questões de gênero no período da ocupação no Instituto. A percepção de que as problemáticas da sociedade se refletem dentro do espaço escolar serviu para questionar a divisão sexual do trabalho e suas funções, por isso houve a divisão igualitária de tarefas. Nesse sentido, as definições dos papéis de gênero setorizados a determinadas funções foi algo combatido dentro desse espaço criado pelos jovens.

Essa abertura sobre as questões de gênero, segundo os relatos dos estudantes “OCUPA IF CABEDELO”, possibilitou a maior diversidade de debates dentro do espaço escolar, a partir de palestras, de oficinas, de um contato mais direto e a união dos estudantes. Esse processo possibilitou a criação de um canal de diálogo com os estudantes em que poderiam se manifestar e expor suas vivências, mas além de tudo, poder entrar em contato com a pluralidade de discussões.

Nesse sentido, por meio dos resultados, torna-se perceptível uma maior quantidade de participação de alunos mais jovens, concentrados no primeiro ano, e, a partir dos relatos, demonstra-se uma mudança na relação com a escola por meio de uma maior apropriação do espaço escolar pelos alunos participantes desta pesquisa.

Ao nos atentarmos para a presença de palavras chaves nos relatos desses jovens, percebemos que emergem termos como direito, voz, união, compartilhar, transformar, 
falas significativas, que em síntese, expressam o que o envolvimento na ocupação simbolizou enquanto prática para os ocupantes.

Por isso, os estudantes passaram a abrir portas, ocupar escolas e se representar como lideranças nos movimentos, se dividindo, se organizando, e, principalmente imprimindo um modo de operar e propor demandas. A rebeldia inesperada dos estudantes contempla uma mudança de perspectiva, agora eles que ensinam.

\section{Referências}

AGENDA JUVENTUDE BRASIL. Pesquisa nacional sobre perfil e opinião dos jovens brasileiros 2013. Brasília: Participatório: Observatório Participativo da Juventude, 2013. Disponível em: http://bibjuventude.ibict.br/jspui/bitstream/ 192/91/1/SNJ_agenda_2013.pdf. Acesso em: 29 de ago. 2019.

BRASIL. Lei $\mathrm{n}^{\mathrm{o}} 12.852$, de 5 de agosto de 2013. Institui o Estatuto da Juventude e dispõe sobre os direitos dos jovens, os princípios e diretrizes das políticas públicas de juventude e o Sistema Nacional de Juventude-SINAJUVE. Diário Oficial da União, 2013.

BRASIL. Estatuto da Criança e do Adolescente. 15 ed. São Paulo: Saraiva, 2007.

BRASIL. Lei ${ }^{\circ}$ 4.530/2004. Projeto de Lei e Institui a aprovação do Plano Nacional de Juventude e dá outras providências. Brasília, DF: Comissão Especial de Políticas Públicas para a Juventude [2004]. Disponível em: http://www.dhnet.org.br/dados/pp/a_pdfdht/plano_nac_juventude.pdf. Acesso em: 29 de ago 2019.

BRASIL. Lei $\mathrm{n}^{\circ}$ 9.979, de 5 de julho de 2000. Abre ao Orçamento Fiscal da União, em favor da Justiça Eleitoral, crédito Suplementar no valor de $\mathrm{R} \$ 155.000 .000,00$, para reforço de dotações consignadas no vigente orçamento. Diário Oficial [da] República Federativa do Brasil: seção 1, Brasília, DF, ano 138, n. 129, p. 4, 6 jul. 2000.

BRINGEL, Breno. O futuro anterior: continuidades e rupturas nos movimentos estudantis do Brasil. Eccos Revista Científica, v. 11, n. 1, p. 97-121, 2009. Disponível em:https://periodicos.uninove.br/index.php?journal=eccos\&page $=$ article\&op=view\&pat $\mathrm{h} \% 5 \mathrm{~B} \% 5 \mathrm{D}=1529$. Acesso em: 29 de ago. 2019.

CALIARI, H. F.; HELMER, F. P. Juventude, políticas sociais e movimentos culturais ligados à música (funk, reggae, hip hop, rock) no município de Vitória: uma análise das Políticas Públicas de Juventude. 2006. Dissertação (Mestrado em Política Social) Universidade Federal do Espírito Santo, Vitória, 2006. Disponível em: http://portais4.ufes.br/posgrad/teses/tese_3491_Hingridy\%20Fassarella\%20Caliari.pdf. Acesso em: 29 de ago. 2019. 
CAMPOS, Antonia J. M.; MEDEIROS, Jonas; RIBEIRO, Marcio M. Escolas de luta. São Paulo: Veneta, 2016.

CASTELS, Manuel. Redes de indignação e de esperança. Rio de Janeiro: Jorge Zahar Editor, 2013.

CASTELLS, Manuel. Sociedade em rede. São Paulo: Paz e Terra, 1999. Vol. I.

CINTRA, André; MARQUES, Raissa. UBES Uma rebeldia consequente: a história do movimento estudantil secundarista do Brasil. Belo Horizonte, 2009. E-book. Disponível em: https://vdocuments.site/livro-ubes-uma-rebeldia-consequente.html. Acesso em: 29 de ago. 2019.

COELHO, C. N. P. A contracultura: o outro lado da modernização autoritária. In: RISÉRIO, A. Anos 70: trajetórias. São Paulo, Iluminuras, 2006.

COELHO, C. N. P. A transformação social em questão: as práticas sociais alternativas durante o regime militar. 1990. Tese (Doutorado) - Universidade de São Paulo, São Paulo, 1990.

DAYRELL, Juarez; REIS, Juliana Batista. Juventude e escola: reflexões sobre o ensino da sociologia no ensino médio. In: CONGRESSO BRASILEIRO DE SOCIOLOGIA, 13., 2007, Recife. Anais [...] Recife: UFPE, 2007. Disponível em: https:/ensinosociologia.milharal.org/files/2010/09/Dayrell-e-Reis2007-Juventude-Esco la.pdf. Acesso em: 29 de ago. 2019.

DIAS, Anna Beatriz Ramos; CHAVES, Bruno Alexandre; TOSCANO, Geovânia; MENDES, Raphaella Ferreira. Ocupar e resistir: Análise sobre o movimento "ocupa IFPB CABEDELO". In: COLÓQUIO INTERNACIONAL DE PESQUISA EM EDUCAÇÃO SUPERIOR, 4., Anais. 2017. Disponível em: https://docplayer.com.br/77928842-Caderno-de-resumos-organizadoras-profa-draedineide-jezine-profa-dra-uyguaciara-vel oso-castelo-branco.html. Acesso em: 29 de nov. 2017.

DIAS, Anna Beatriz Ramos. Coletivo Rouxinol de Teatro do Oprimido (Cabedelo/PB) - arte, educação e protagonismo juvenil. 2019. (Trabalho de Conclusão de Curso) Departamento de Ciências Sociais, Centro de Ciências Humanas, Letras e Arte, João Pessoa, 2019.

FARIAS, Thayna Rimar. Relação IFPB e comunidade jardim Jericó, município de Cabedelo/ PB: O Que Eles Esperam De Nós? 2016. (Trabalho de Conclusão de Curso) - Curso de Curso Técnico Integrado em Meio Ambiente, Instituto Federal de Educação, Ciência e Tecnologia da Paraíba, Cabedelo - PB, 2016.

FORACCHI, Marialice Mencarini. A juventude na sociedade moderna. Livraria Pioneira Editora, 1972. 
GOHN, Maria da Glória. A sociedade brasileira em movimento: vozes das ruas e seus ecos políticos e sociais. Caderno CRH, v. 27, n. 71, p. 431-441, 2014. Disponível em: https://www.scielo.br/pdf/ccrh/v27n71/a13v27n71.pdf. Acesso em: 29 de ago. 2019

GOHN, Maria da Glória. Movimentos sociais na contemporaneidade. Revista Brasileira de Educação. v.16, n.47, p. 333-361, 2011. Disponível em: https://www.mprj.mp.br/documents/20184/172155/movimentos_sociais_na_contempor aneidade.pdf. Acesso em: 29 de ago. 2019

GONZÁLEZ, Jorge Luis Cammarano; MOURA, Marcilene Rosa Leandro. Protagonismo juvenil e grêmio estudantil: a produção do indivíduo resiliente. Eccos Revista Científica, v. 11, n. 2, p. 375-392, 2009. Disponível em: https://www.redalyc.org/ pdf/715/71512786004.pdf. Acesso em: 20 de set. 2019

GROPPO, Luís Antonio; SILVA, Rodrigo. Experiência e subjetivação política nas ocupações estudantis no Rio Grande do Sul. Estudos Avançados, v. 34, n. 99, p. 409424, 2020. Disponível em: https://www.scielo.br/pdf/ea/v34n99/1806-9592-ea-34-99409.pdf. Acesso em: 4 de jul. 2020

IANNE, Octavio. O jovem radical. In: BRITTO, Sulamita de (org.). Sociologia da Juventude, I: da Europa de Marx à América Latina de Hoje. Rio de Janeiro: Zahar editores, 1963, p. 225-242.

MARTINS FILHO, João Roberto. Movimento estudantil e militarização do estado no Brasil: 1964-1968. 1986. Dissertação (Mestrado) — Universidade Estadual de Campinas, Instituto de Filosofia e Ciências Humanas, Campinas, SP, 1986. Disponível em: http://www.repositorio.unicamp.br/handle/REPOSIP/279831. Acesso em: 29 de ago. 2019.

MEDEIROS, Alexsandro. Estatuto da Juventude. Site Sabedoria Política, Parintins (AM), dez. 2016. Disponível em: https://www.sabedoriapolitica.com.br /products/estatuto-da juventude/. Acesso em: 22 jul. 2018.

MENDES, Rapahella F. Das ruas às escolas: análise sobre o movimento de ocupação do Instituto Federal de Cabedelo-PB. In: CONGRESSO BRASILEIRO DE SOCIOLOGIA, 19., 2019, Florianópolis. Anais [...]. Florianópolis: UFSC, 2019. Disponível em: http://www.sbs2019.sbsociologia.com.br/arquivo/downloadpublic?q=YToyOntzOjY6In BhcmFtcyI7czozNDoiYToxOntzOjEwOiJJRF9BUIFVSVZPIjtzOjM6IjkyNCI7fSI7czo xOiJoIjtzOjMyOiJmYTZjMzQ5YzNiMDE3NTMxMzZ1YTkyN2NmNTUwYWQ3MSI 7fQ\%3d\%3d. Acesso em: 29 de nov. 2019.

MENDES, Rapahella F. Movimento de ocupação do IFPB/Cabedelo-PB. 2017. (Trabalho de conclusão de curso) - Licenciatura em Ciências Sociais, Universidade Federal da Paraíba, João Pessoa, 2017. 
MEGA BO; NB. [Compositores e intérpretes]. Quilombo do Futuro. Tijolo Publishing. 2016. Disponível em: https://www.youtube.com/watch?v=TB5fQ-Xbeko\&ab_channel =MagaBo-Topic. Acesso em: 4 out. 2019.

MINAYO, M. C. S. O desafio do conhecimento: pesquisa qualitativa em saúde. 7. ed. São Paulo: Hucitec, 2000. Disponível em: https://www.scielo.br/pdf/csc/v12n4/27.pdf. Acesso em: 22 jul. 2018.

MITCHELL, Don. The right to the city: social justice and the fight for public space. New York: Guilford Press, 2003.

MORIN, Edgar. A cabeça bem-feita: repensar a reforma, reformar o pensamento. Rio de Janeiro: Bertrand Brasil, 2010.

PAIS, J.M. Culturas juvenis. Lisboa: Imprensa Nacional Casa da Moeda,1993.

POERNER, Artur J. O poder jovem: história da participação políticas dos estudantes brasileiros. 5.ed. Rio de Janeiro: Bookling, 2004.

SPOSITO, M. P. Algumas hipóteses sobre as relações entre movimentos sociais, juventude e educação. Revista Brasileira de Educação, São Paulo, n. 13, p. 73-94, 2000. Disponível em: https:/ensinosociologia.pimentalab.net/files/2010/09/Sposito2000.pdf. Acesso em: 22 jul. 2018.

Recebido em: 31/08/20.

Aceito em: 25/10/20. 